\title{
Effect of Gender-Specific Adult Bovine Serum on Gene Expression During Myogenesis
}

\author{
Eun $\mathrm{Ju} \mathrm{Lee}^{1, \mathrm{a}}$, Smritee Pokharel ${ }^{2, \mathrm{a}}$, Jiehoe $\mathrm{Kim}^{1}$, Sang-Sup $\mathrm{Nam}^{3}$ and Inho Choi ${ }^{1,2 *}$ \\ ${ }^{1}$ School of Biotechnology and ${ }^{2}$ Department of Biotechnology, Yeungnam University, Gyeongsan, Korea; ${ }^{3}$ College of \\ Veterinary Medicine, Konkuk University, Seoul, Korea
}

\begin{abstract}
Gender specificity in muscle growth and development is well known. Genesis of muscle is dependent on proliferation and differentiation potential of resident myogenic satellite cells (MSCs) present in muscle fibers. Multipotential capacity of forming myocyte, osteocyte, and adipocyte like cell makes MSCs a unique stem cell. To understand the molecular mechanism involved in determination of muscle quality due to difference in hormone concentration of different gender of animals, MSCs were isolated from bovine skeletal muscle and cultured in male, female, and castrated serum supplemented media. DNA microarray used consisted of 24,000 spots with 70 mer oligo in each spot. A total of 88 genes were up-regulated and 551 genes were down-regulated by more than two fold. Among up-regulated gene, 33, 34, and 21 genes were found up-regulated in cells grown in male, female, and castrated serum, respectively. Interestingly, male serum showed 4, female 11 and castrated male showed 4 genes expressed highly in each gender. Further study on the highly up-regulated gene may unfold the mystery of gender specificity found in muscle development. Also, the identification of differentially expressed genes in gender-specific serum will add information on infrastructure of bovine genome research.
\end{abstract}

(Key words : Serum, Sex Steroid, Myogenesis, Muscle)

\section{INTRODUCTION}

Serum provides oxygen, growth factors, vitamins, co-factors, hormones, trace elements and other ambiguous factors in cell culture (Maurer, 1986). Effect of serum in cell kinetics and metabolism is well known (Øystein et al., 1981). However, serum shows different effect depending on cell and serum type in vitro (Choi et al., 1980). Even though, bovine serum (BS) and horse serum are common in practice, use of porcine, mouse and human serum are still limited. Horse serum is rich in proteins and vitamins but with lower trace elemental concentrations when compared to BS. Similarly, adult bovine serum is rich in protein than fetal bovine serum (FBS), and mouse serum is rich in vitamins (Verlag et al., 1998). Horse serum is widely used for differentiation (Yaffe et al., 2006) and porcine serum to grow mycoplasma and viruses. Adult bovine serum has been used for BHK cell growth (Strouken et al., 1994) and $H$ pylori culture (Shibayama et al., 2006). Thus, the factors present in serum makes the choice of serum a critical issue in cell culture.
In vitro culture of muscle cell requires serum (Haba et al., 1968). Ultra structural similarity in in vitro development of myofibrils and sarcoplasmic reticulum with in vivo condition has been reported during myogenesis by use of serum (Shimada et al, 1967). Myogenesis refers to the formation of myofibrils followed by activation of myoblasts and eventually its differentiation into myotubes (Hawke and Garry, 2001). Formation of myotube followed by the myoblast fusion is a highly regulated process that is associated with spatial and functional localization of molecules. Two main stages involved are; subset of differentiated myoblast which fuse together to form a nascent myotube with limited number of myonuclei, and subsequently differentiated myoblast fuse together with nascent myotube to form mature myofibrils (Pavlath, 2010).

Involvement of transcription regulatory factors, growth factors, and calcium regulatory proteins has been widely studied in myogenesis (Buckingham et al., 2003; Hayashi et al., 2000; Kaufmann et al., 1999). Four main helix loop helix transcription factor involved in the earlier stage of

${ }^{\mathrm{a}}$ These authors contributed equally to this work

* Corresponding author: Dr. Inho Choi, School of Biotechnology, Yeungnam University, Gyeongsan 712-749, Republic of Korea, Tel: +82-53-810-3024, Fax: +82-53-810-4657, E-mail: inhochoi@ynu.ac.kr 
myognesis are MyoD, Myf5, myogenin and MRF4. The expression patterns among these factors determine the fate of skeletal muscle. Humoral factor regulates expression of specific myogenic helix-loop-helix in adult muscle(Hughes, et.al., 1993). Thus, the niche of skeletal muscle comprises of proliferating satellite cells $\left(\mathrm{Pax}^{+} / \mathrm{MyoD}^{+} / \mathrm{Myogenin}^{-}\right)$, small population of reserve cells $\left(\operatorname{Pax} 7^{+} / \mathrm{MyoD}^{-} / \mathrm{Myogenin}^{-}\right)$, differentiating cells $\left(\operatorname{Pax} 7^{-} / \mathrm{MyoD}^{+} / \mathrm{Myogenin}^{+}\right)$and the transition stage cells $\left(\mathrm{Pax}^{+} / \mathrm{MyoD}^{+} / \mathrm{Myogenin}^{+}\right.$) (Halevy et al., 2004).

Gender and nutritional status of an animal has been considered as major factors that impact in muscle development. Studies have revealed that muscle growth and differentiation is higher in male than in female and castrated male animals (Essien et al., 1988; Miller et al., 1993). Sexrelated difference in muscle has also been evident from a study on skeletal muscle fatigue resistance which has been correlated with differences in fiber type composition(Wüst et al., 2007). Previously, we have determined different factors present in gender specific adult bovine serum(Kim et al., 2011; Lee et al., 2007). We have also shown that the gender specific adult bovine serum(GSBS) is responsible for myogenesis of adult bovine MSCs (Lee et al., 2012). In order to continue our research toward identification of gender specific factors involved in muscle development, here we tried to analyze the effect of GSBS during myogenesis in MSCs.

\section{MATERIALS AND METHODS}

\section{Tissue and serum collection}

All research materials used in this study were provided by the Bovine Genome Resources Bank, Yeungnam University, Gyeongsan, Korea. Skeletal muscle from hind limb of male ranging from 24-26 months in age with body weight of $550-600 \mathrm{~kg}$ was collected in air-tight plastic bags from a regional slaughterhouse at Yeongcheon, Gyeongsanbuk-do, Republic of Korea. Similarly, blood samples were collected from 9 different Hanwoo. Three sets were formulated for extraction of GSBS. Each set comprised of a male, a female and a castrated male.

\section{Serum Preparation}

Collected blood samples from all $9($ male $=3$, female $=3$, and castrated male $=3$ ) bovine individuals were centrifuged at 5,000 rpm for $20 \mathrm{~min}$ at $4{ }^{\circ} \mathrm{C}$ and stored at $4{ }^{\circ} \mathrm{C}$ overnight. The supernatant was transferred to a new tube and stored at $-20{ }^{\circ} \mathrm{C}$. The frozen supernatant was thawed and centrifuged at 7,000 rpm for $20 \mathrm{~min}$ at $4^{\circ} \mathrm{C}$ and collected in a new tube. Heat inactivation was done by heating the serum at 56 ${ }^{\circ} \mathrm{C}$ for $30 \mathrm{~min}$ and was filtered through $0.2 \mu \mathrm{m}$ diameter pore-sized filter. Thus obtained serum was stored in $-20^{\circ} \mathrm{C}$ until use.

\section{Hormonal analysis}

Testosterone, 17ß-estradiol $\left(\mathrm{E}_{2}\right)$ and estrone $\left(\mathrm{E}_{1}\right)$ in the extracted serum were measured by enzyme-linked immunosorbent assay (ELISA; DRG International Inc., N.J. USA) following manufacturer's instruction. In brief, standard controls of known concentration, or test serum and enzyme conjugate, were added in a specific-antibody-coated microtiter well and incubated for 1-2 $\mathrm{h}$ at room temperature. Three subsequent washing to remove the unbound antibody was followed by addition of substrate solution and was incubated for 15-30 min. Finally, the enzymatic reaction was terminated by adding stop solution and the absorbance was measured at $450 \mathrm{~nm}$ within $10 \mathrm{~min}$ using an ELISA plate reader (Microplate auto reader; Bio-Rad, Hercules, CA, USA).

\section{MSC isolation and primary culture}

Collected skeletal muscle was briefly rinsed with phosphate buffered saline (PBS) and minced into fine pieces using sterilized scissors. The minced tissue were digested in trypsin-EDTA (GIBCO, Carlsbad, CA, USA) for $2 \mathrm{~h}$ in shaking water bath at $37^{\circ} \mathrm{C}$ and was followed by centrifugation at $700 \mathrm{rpm}$ for $3 \mathrm{~min}$. The upper phase was filtered through $40 \mu \mathrm{m}$ pore size cell strainer and the filtrate was again centrifuged at $2,500 \mathrm{rpm}$ for $20 \mathrm{~min}$. Thus obtained cell pellet was washed three times using Dulbecco's Modified Eagle's Medium(DMEM; HyClone Laboratories, Logan, UT, USA) containing $1 \%$ penicillin/ streptomycin (Invitrogen, Carlsbad, CA, USA). The cells were cultured in a $100 \mathrm{~mm}$-diameter culture dish using DMEM supplemented with 10\% FBS (Hyclone Laboratories), 1\% penicillin/ streptomycin, and $0.1 \%$ ampho- tericine (GIBCO) by incubating at $37^{\circ} \mathrm{C}$ in an atmosphere of $5 \% \mathrm{CO}_{2}$. The primary MSC culture was observed closely with change in medium every 48 hours. 


\section{MSC differentiation in GSBS}

MSCs cultured in 10\% FBS were enumerated and subcultured with equal number in each plate to get passage 1 . The first passage of cells were allowed to attach in $10 \%$ FBS media for $24 \mathrm{hrs}$, switched into $10 \%$ of GSBS supplemented media (Male serum, MS Female serum, FS; or Castrated male serum, C-MS) and cultured in it until 10 day.

\section{Real time RT-PCR}

Total RNA was extracted from differentiated myotube formed cells using Trizol $^{\mathrm{TM}}$ reagent (Invitrogen) according to the manufacturer's protocol. RNA concentration of samples was measured using an ND-1000 spectrophotometer (NanoDrop Technologies, Wilmington, DE, USA) and was stored in diethylpyrocarbonate-treated water at $-80^{\circ} \mathrm{C}$ until use. cDNA synthesis and Real time RT-PCR was performed according to Lee et al., (2011). Forward and reverse primers for myogenin tgggegtgtaaggtgtgtaa $(\mathrm{F})$ and tgcaggcgetctatgtactg (R) were designed with Primer 3 software (http://frodo.wi. mit.edu) using sequence information listed at the National Center for Biotechnology Information. Real time PCR was carried out under the following conditions: pre-denaturation of the synthesized cDNA at $95^{\circ} \mathrm{C}$ for $10 \mathrm{~min}$, followed by 40 cycles of denaturation at $95^{\circ} \mathrm{C}$ for $33 \mathrm{sec}$, annealing at $57^{\circ} \mathrm{C}$, and extension at $72^{\circ} \mathrm{C}$ for 33 sec. Proper amplification of the genes of interest was verified by melting point analysis and $1.2 \%$ agarose gel electrophoresis.

\section{DNA Microarray Hybridization}

DNA microarray analysis with a total of eighteen hybridizations was performed to identify differentially expressed genes in myotube formed cells cultured in MS, FS and C-MS. Bovine oligonucleotide microarray generation has been described previously (Lee et al, 2011). In brief, the microarray contained 24,000 oligomers of 70-mer probes which targeted the transcripts of 16,341 genes representing about $70 \%$ of the total number of genes in the bovine genome. DNA microarrays were hybridized as control (MS + FS + C-MS) against MS, FS and C-MS respectively. The synthesis of target cRNA probes was performed using a Low RNA Input Linear Amplification kit (Agilent Technologies, Palo Alto, CA, USA) according to the manufacturer's instructions.

\section{Identification of differentially expressed genes}

Hybridized microarray images were obtained using AXON GenePix 4000B scanner (Axon Instruments, CA) and analyzed by GenePix Pro 6.0 program (Axon Instruments). Data normalization, identification of fold-change and gene classification procedure was done according to our previous study (Lee et al., 2012).

\section{Data base construction for microarray analysis}

To analyze the bovine microarray data, microarray-related information including bovine reference nucleotide sequence identification, amino acid sequence identification, and annotation data were downloaded from NCBI. Based on this initial information, we constructed a web-based sequence database (http://www.bovinebank.kr/chip) to facilitate analysis of the bovine microarray data.

\section{RESULT}

\section{Hormonal analysis}

Hormone levels in serum were analyzed by ELISA. The result showed higher level of testosterone in MS than in FS and C-MS. Whereas $\mathrm{E}_{2}$ level was mostly higher in FS. $\mathrm{E}_{1}$ was relatively higher in MS than other two genders and androstenedione level was maintained in all three MS, FS and C-MS (Table 1).

\section{Differentiation of MSCs}

Bovine MSCs cultured for eight days in 10\% FBS were enumerated and sub-cultured. Cells allowed to attach for 24 hrs were differentiated in 10\% GSBS (MS, FS, and C-MS). All cells cultured with different GSBS showed morphologically distinct cellular stages during myogenesis. Proliferating cells formed long myotube with multiple nuclei on $10^{\text {th }}$ day of differentiation. Cells treated with MS, FS and C-MS showed almost equal amount of myotube formation following myogenic differentiation(Fig. 1A). Real time RT-PCR on myogenin showed similar mRNA expression levels in all MSCs treated with MS, FS and C-MS respectively on $10^{\text {th }}$ day of differentiation (Fig. 1B). 
Table 1. Hormone analysis of GSBS

\begin{tabular}{cccccc}
\hline Set & Sex & $\begin{array}{c}\text { Testosterone } \\
(\mathrm{ng} / \mathrm{ml})\end{array}$ & $\begin{array}{c}17 \beta \text {-estradiol } \\
(\mathrm{ng} / \mathrm{ml})\end{array}$ & $\begin{array}{c}\text { Estrone } \\
(\mathrm{ng} / \mathrm{ml})\end{array}$ & $\begin{array}{c}\text { Androstenedione } \\
(\mathrm{ng} / \mathrm{ml})\end{array}$ \\
\hline \hline \multirow{3}{*}{1} & MS & 6.2 & 0.023 & 0.110 & 0.04 \\
& FS & 0.9 & 0.047 & 0.055 & 0.08 \\
& C-MS & 0.6 & 0.031 & 0.122 & 0.06 \\
\hline \multirow{3}{*}{2} & MS & 13 & 0.068 & 0.194 & 0.05 \\
& FS & 0.6 & 0.054 & 0.050 & 0.05 \\
& C-MS & 1.9 & 0.096 & 0.154 & 0.05 \\
\hline \multirow{3}{*}{3} & MS & 5.6 & 0.078 & 0.602 & 0.09 \\
& FS & 1.0 & 0.105 & 0.381 & 0.06 \\
& C-MS & 0.7 & 0.069 & 0.117 & 0.06 \\
\hline
\end{tabular}

Foot note: Gender specific variation in hormone concentration of adult bovine serum analyzed by ELISA. Highest level of testosterone and estrone is present in male and highest level of estrogen is present in female as compared to each genera.

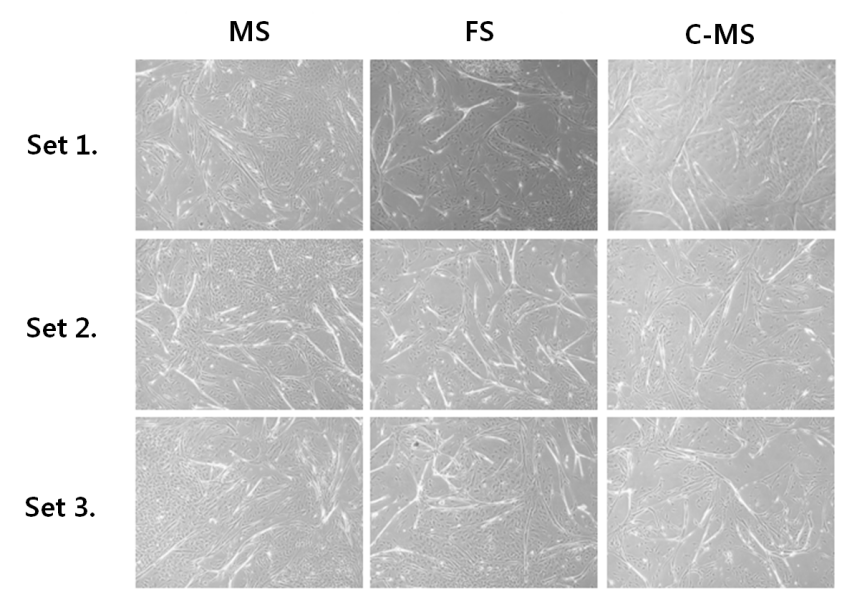

Fig. 1A. MSCs differentiation in GSBS.

Foot note: MSCs cultured in $10 \%$ GSBS supplemented media on day 10. MS, FS and C-MS showed almost similar amount of myotube formation regardless of their hormone specificity.

\section{Hierarchical clustering}

Up-regulated genes in cells cultured with different gender specific bovine serum were identified by DNA microarray analysis. MS, FS and C-MS treated cells were hybridized against control (mixed samples from MS, FS, and C-MS treated group). Genes showing more than two fold up-regulation were selected for further study and were subjected to correlation based clustering. Cells grown in MS and C-MS showed closer relationship during myogenesis than FS. And cells grown in FS showed farthest relation with both the MS and C-MS (Fig. 2).

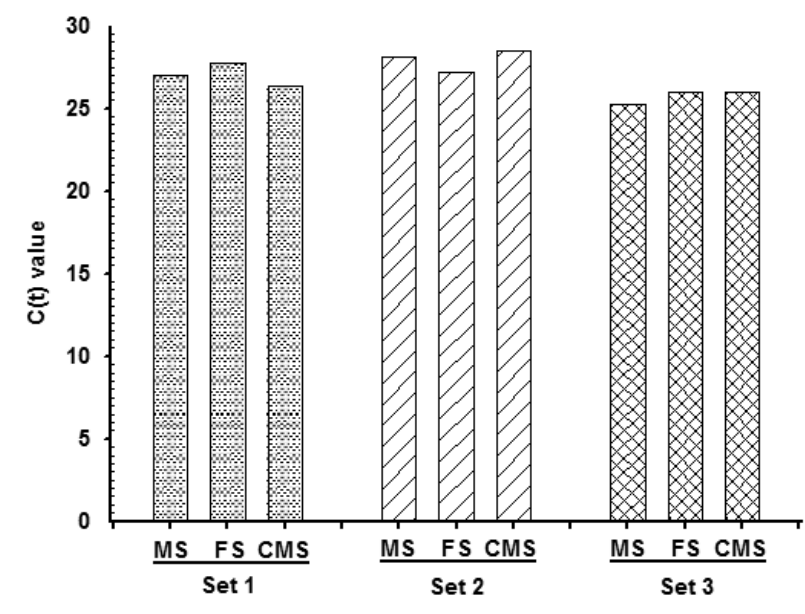

Fig. 1B. Real time RT-PCR on Myogenin expression. Foot note: Cells treated with all three sets of GSBS showed similar myogenin expression pattern.

\section{Microarray analysis}

Microarray analysis identified a total of 551 genes differentially expressed. Among them, 88 genes were up- and 463 genes were down- regulated. MS showed 33, FS showed 34 and C-MS showed 21 genes up-regulation during myogenesis (Table 2). Genes differentially expressed in cells grown in MS, FS and C-MS were analyzed (MS vs. FS and C-MS, FS vs. MS and C-MS and C-MS vs. MS and FS treated cells) (Table 3). MS when compared with FS and C-MS showed 10 and 7 genes up-regulated, respectively. In contrast, FS when compared with MS and C-MS showed 14 and 15 up-regulated genes, respectively. C-MS showed least 


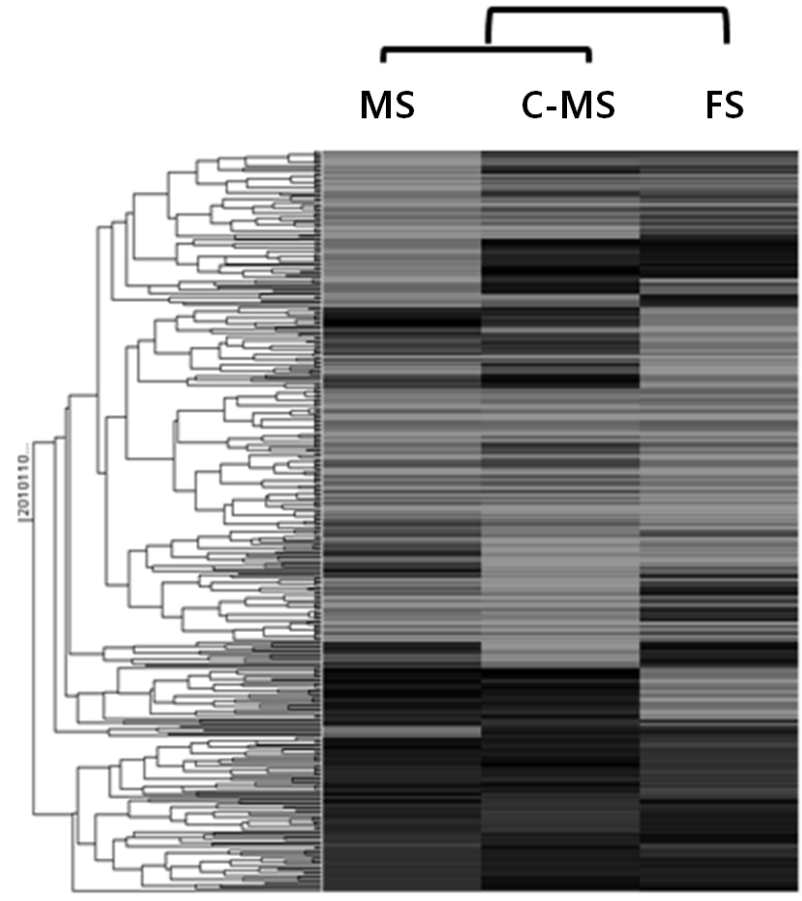

Fig. 2. Hierarchical cluster analysis of gene expression profiles.

Foot note: Green indicates genes up-regulated in MSCs and red indicates genes up-regulated in MS, FS and C-MS, respectively.

Table 2. Microarray analysis during myogenesis in different GSBS

\begin{tabular}{lc}
\hline Serum & Genes \\
\hline \hline MS & 33 \\
FS & 34 \\
C-MS & 21 \\
\hline MS > FS & 10 \\
MS $>$ C-MS & 7 \\
\hline FS $<$ MS & 14 \\
FS $>$ C-FS & 15 \\
\hline C-MS $>$ MS & 5 \\
C-MS $>$ FS & 6 \\
\hline All & 0 \\
\hline
\end{tabular}

Foot note: Number of genes up-regulated by gender specific adult bovine serum.

number of genes up-regulated, i.e, 5 against MS and 6 against FS (Table 2). Up-regulated genes when compared to identify gender specificity during myogenesis, revealed 11 genes in FS, 4 in MS and 4 in C-MS supplemented cells (Table 3).

\section{DISCUSSION}

This study is an attempt to see the effect of GSBS on muscle formation. MS/FS/C-MS were isolated, analyzed and used in bovine MSCs culture for myogenic differentiation. Hormones in serum of MS, FS and C-MS were analyzed, which showed gender specificity. MS showed higher concentration of testosterone and $\mathrm{E}_{1}$ levelthan FS and C-MS. Higher female steroid hormone, $\mathrm{E}_{2}$ level was observed in FS when compared with MS and C-MS. Variation of both $\mathrm{E}_{2}$ and $E_{1}$ concentration among FS can be justified with the fact that the hormone levels vary during the estrous cycle (Dobson et al., 1974) and the variation in testosterone among MS can also be due to the age related factor (Barth et al., 2008).

Morphologically, cells cultured in all gender specific serum showed distinct cellular stages during myogenesis. Proliferating cells after 24 hour showed contact inhibition followed by cell alignment, fusion and then formation of myotube. Multi-nucleated myotubes were abundant in all cells and when compared between MS, FS and C-MS treated cells, no difference in myotube morphology and amount was observed regardless of difference in serum hormone concentrations.

In order to confirm the proliferating cells were differentiated into myotube following myogenesis, myogenin gene was analyzed by real-time RT-PCR. Myogenin is considered to be a key regulatory factor for myogenic differentiation (Wright et al., 1989). It is a member of MyoD family transcription factor like Myf5, MyoD and MRF4 (Braun et al, 1989) and is involved at later stages of myofiber fusion, which is co expressed with p21 (Vicente A, 1996). Expression analysis of myogenin mRNA showed similar level in all serum treated groups which also agrees with the similar amount of myotube formed by serum as seen in Fig. 1. Interestingly, regardless of different hormone concentration in different gender of the species, no significant difference in the amount of myotube formation and myogenin expression was observed following myogenic differentiation.

Number of attempts has been made to identify the genes differentially expressed during myogenesis by microarray technique (Shen et al., 2003; Sterrenburg et. al., 2004; Moran et. al., 2002). Hierarchical cluster analysis on genes showed closer relation between MS and C-MS treated MSCs. In spite of closer relation of MS and C-MS in hierarchical clustering and similar myotube forming capacity of all three GSBS in cell culture; difference in serum steroid hormonal 
Table 3. Microarray analysis

\begin{tabular}{|c|c|c|c|c|}
\hline & Annotation & Male & Female & Castrated \\
\hline \multirow{4}{*}{ MS } & Calcineurin-like-phosphoesterase domain-containing protein 1 & 3.2 & 0.7 & 1.4 \\
\hline & Poly (ADP-ribose) polymerase family, member 14 & 2.6 & 0.7 & 1.1 \\
\hline & DnaJ homolog subfamily $\mathrm{C}$ member 14 & 2.2 & 0.8 & 1.1 \\
\hline & A-kinase anchor protein 6 & 2.2 & 1.1 & 1.0 \\
\hline \multirow{11}{*}{ FS } & Biotinidase precursor & 0.8 & 4.4 & 1.4 \\
\hline & Nuclear factor NF-kappa-B p105 subunit & 1.4 & 3.8 & 1.4 \\
\hline & Microtubule-associated protein RP/EB family member 2 & 0.9 & 2.6 & 1.1 \\
\hline & Gamma-glutamyltransferase 7 & 1.1 & 2.6 & 1.3 \\
\hline & Poliovirus receptor-related 1 isoform 1 & 0.8 & 2.2 & 0.9 \\
\hline & Numb-like protein & 0.9 & 2.2 & 1.2 \\
\hline & $\mathrm{D}(2)$ dopamine receptor & 1.0 & 2.2 & 1.0 \\
\hline & Envoplakin & 1.0 & 2.1 & 0.8 \\
\hline & CK729724.1 & 0.6 & 2.0 & 0.9 \\
\hline & Large neutral amino acids transporter small subunit 4 & 1.1 & 3.4 & 0.8 \\
\hline & Hypothetical protein PFLU2001, DN642636.1 & 1.1 & 3.4 & 1.2 \\
\hline \multirow{4}{*}{ C-MS } & Hypothetical protein PANDA_013144, 31332_CL5Contig1 & 0.9 & 0.7 & 2.3 \\
\hline & Inactive hydroxysteroid dehydrogenase-like protein 1 & 0.8 & 0.8 & 2.1 \\
\hline & DIP2 disco-interacting protein 2 homolog C-like & 1.3 & 1.4 & 3.3 \\
\hline & GC-rich promoter binding protein 1-like 1 isoform 1 & 1.0 & 1.0 & 2.1 \\
\hline
\end{tabular}

Foot note: List of genes with at least 2 fold up-regulation during myogenic differentiation by GSBS.

concen- tration and difference in highly up-regulated genes among different gender make us speculate that, the difference in gender specificity may be either due to direct effect of steroids or other intermediatory factors.

In this experiment, we analyzed differentially expressed genes in MS, FS and C-MS treated bovine MSCs. We identified a total of 551 genes differentially expressed during myogenesis. Among which 88 genes were up-regulated and 463 genes were down-regulated. Only the genes showing two or more than two fold up-regulation were chosen for the study. As expected, correlation based clustering on those genes showed closer relationship between MS and C-MS during myogenesis than that with FS (Fig. 3). Among 88 up-regulated genes, 19 genes showed gender specificity. Eleven genes showed specificity in FS, 4 in MS and 4 in C-MS respectively. Almost all the genes with higher fold expression in each gender were related to myogenesis.

In male, calcinurin-like phosphoesterase domain-containing protein 1 was highly expressed. It can be speculated that like calcinurin, this gene may act with $\mathrm{Ca}^{2+} /$ calmodulin in skeletal myogenesis (Olson et al., 2000). Yoshioka et al., reported higher expression of genes related to cytoskeleton, mitochondrial, lipid, and amino acid metabolisms was detected in female skeletal muscles. In female, biotinidase precursor involved in biotin metabolism and NF-kappa-Bp 105 subunit showed higher fold expression than rest 9 genes. Biotinidase precursor has also been reported in skeletal muscle in bovine (Sadkowski et al., 2009). Similarly, role of NFk- $\beta 105$ subunit in skeletal muscle myogenesis has been defined as a negative regulator of proliferation (Bakkar et al., 2010). DIP2 disco interacting protein 2 homolog $C$ like gene up-regulated in C-MS treated cells is a novel finding. We report here for the first time its involvement in skeletal myogenesis.

To conclude, although the differences in steroid hormone concentration did not show significant morphological difference during myotube formation, gene expression profile in our study is evident that the steroids are directly or indirectly involved in muscle formation. It may be interesting to study the effect of steroids in these genes to unfold the 
Lee et al.; Effect of GSBS on Myogenesis

possible underlying mechanisms behind difference in muscle development among different gender of species.

\section{ACKNOWLEDGEMENT}

The authors wish to thank Drs. Abdul R. Bhat, Majid Rasool Kamli and K.M.A Tareq for critical reviewing of the manuscript. Gender specific adult bovine serums were used from the Bovine Genome Resources Bank. This work was supported by the Cooperative Research Program for Agriculture Sciences \& Technology Development (Project No. PJ007472), Rural Development Administration, Republic of Korea.

\section{REFERENCES}

Buckingham, M., Bajard, L., Chang, T., Daubas, P., Hadchouel, J., Meilhac, S., Montarras, D., Hadchouel, J., Meilhac, S. and Montarras, D. 2003. The formation of skeletal muscle: from somite to limb. J. Anat. 202:59-68.

Bakkar, N. and Guttridge, D. C. 2010. NF-kB Signaling: A Tale of Two Pathways in Skeletal Myogenesis. Physiol. Rev. 90: 495-511.

Barth, A. D., Brito, L. F. and Kastelic, J. P. 2008. The effect of nutrition on sexual development of bulls. Theriogenology. 70: 485-494.

Braun, T., Buschhausen-Denker, G., Bober, E., Tannich, E. and Arnold, H. H. 1989. A novel human muscle factor related to but distinct from MyoD1 induces myogenic conversion in 10T1/2 fibroblasts. EMBO J. 8:701-709.

Choi, Y. C., Morris, G. M., Lee, F. S. and Sokoloff, L. 1980. The Effect of Serum on Monolayer Cell Culture of Mammalian Articular Chondrocytes. Connective tissue research. 7:105-112.

Dobson, H. and Dean, P. D. 1974. Radioimmunoassay of oestrone oestradiol-17a and-17b in bovine plasma during the oestrous cycle and last stages of pregnancy. J. Endocrinol. 61:479-486.

Essien, A. I. and Fetuga, B. L. 1988. Muscle growth and development in the indigenous Nigerian pigs as influenced by age, sex and body weight. The Journalof Agricultural Science. 110:619-625.

Haba, G. D., Cooper, G. W. and Elting, V. 1968. Myogenesis of striated muscle in vitro: Hormone and serum requirements for the development of glycogen synthetase in myotubes. Journal of Cellular Physiology. 72:21-27.

Halevy, O., Piestun, Y., Allouh M. Z., Rosser, B. W. C., Maurer, H. 1986. Towards chemically-defined, serum-free media
Rinkevich, Y., Ram Reshef, R., Rozenboim, I., Wleklinski-Lee M. and Yablonka-Reuven, Z. 2004. Pattern of Pax7 Expression During Myogenesis in the Post hatch Chicken Establishes a Model for Satellite Cell Differentiation and Renewal. Developmental Dynamics. 231:489-502.

Hawke, T. J. and Garry, D. J. 2001. Myogenic satellite cells: physiology to molecular biology. J. Appl. Physiol. 91: 534-551.

Hayashi, S., Aso, H., Watanabe, K., Nara, H., Rose, M. T., Ohwada, S. and Yamaguchi, T. 2000. Sequence of IGF-I, IGF-II, and HGF expression in regenerating skeletal muscle. Histochemistry and Cell Biology. 122:427-434.

Hughes, S. M., Taylor, J. M., Tapscott, S. J., Gurley, C. M., Carter, W. J. and Peterson, C. A. Selective accumulation of MyoD and myogenin mRNAs in fast and slow adult skeletal muscle is controlled by innervation and hormones. Development. 118:1137-1147.

Kim, J., Kim, M., Nahm, S. S., Lee, D. M., Pokharel, S. and Choi, I. 2011. Characterization of Gender-Specific Bovine Serum. Animal Cells and Systems. 15:147-154.

Kaufmann, U., Joachim, Kirsch, J., Irintchev, A., Wernig, A. and Starzinski-Powitz1, A. 1999. The M-cadherin catenin complex interacts with microtubules in skeletal muscle cells: implications for the fusion of myoblasts. Journal of Cell Science. 112:55-67.

Lee, D. M., Bajracharya, P., Lee, E. J., Kim, J. E., Lee, H. J., Chun, T., Kim, J., Cho, K. H., Chang, J. S., Hong, S. K. and Choi, I. 2011. Effects of Gender-Specific Adult Bovine Serum on Myogenic Satellite Cell Proliferation, Differentiation and Lipid Accumulation. In Vitro Cell Develop Biol-Animal. 47:438-44

Lee, D. M., Choi, M. S., Woo, G. I., Shin, Y. M., Lee, K. H., specific Bovine Serum Supplemented Medium on Cell Culture. J. Anim. Sci. and Tech. 51:413-420.

Lee, E. J., Bajracharya, P., Lee, D. M., Kang, S. W., Lee, Y. S., Lee, H. J, Hong, S. K., Chang, J., Kim, J. W., Schnabel, R. D., Taylor, J. F. and Choi, I. 2011. Gene Expression Profiles During Differentiation and Transdifferentiation of Bovine Myogenic Satellite Cells. Genes \& Genomics. 34:133-148.

Lee, E. J., Choi, J., Hyun, J. H., Cho, K. H., Hwang, I. H., Lee, H. J., Chang, J. S. and Choi, I. 2007. Steroid effects on cell proliferation, differentiation and steroid receptor gene expression in adult bovine muscle satellite cells. Asian-Aust J. Anim. Sci. 20:501-510. Cheon, Y., Chun, T. and Choi, I. 2009. Effect of Gender- 
for mammalian cellculture. In R. Freshney (Eds.), Animal cell culture: A Practical approach. IRL Press, Oxford. Pp.

Miller, A. E. J., MacDougall, J. D, Tarnopolsky, M. A, and Sale, D. G. 1993. Gender differences in strength and muscle fiber characteristics. European Journal of Applied Physiology and Occupational Physiology. 66:254-262.

Moran, J. L., Li, Y., Hill, A. A., Mounts, W. M. and Miller, C. P. 2002. Gene expression changes during mouse skeletal myoblast differentiation revealed by transcriptional profiling. Physiol. Genomics. 10:103-111.

Olson, E. N. and Williams, R. S. 2000. Remodeling muscles with calcineurin. Bioessays. 22:510-9.

Pavlath, G. K. 2010. Spatial and functional restriction of regulatory molecules during mammalian myoblast fusion. Experimental Cell Research. 316:3067-3072.

Rønning, O. W., Lindmo, T., Pettersen, E. O. and Seglen, P. O. 1981. Effect of serum step-down on protein metabolism and proliferation kinetics of NHIK 3025 cells. Journal of Cellular Physiology. 107:47-57.

Shen, X., Collier, J. M., Hlaing, M., Zhang, L., Delshad, E. H., Bristow, J. and Bernstein, H. S. 2003. Genome-wide examination of myoblast cell cycle withdrawal during differentiation. Dev. Dyn. 226:128-138.

Shibayama, K., Nagasawa, M., Takafumi Ando, Minami, M., Wachino, J., Suzuki, S. and Arakawa, Y. 2006. Usefulness of Adult Bovine Serum for Helicobacter pylori Culture Media. J Clin Microbiol. 44:4255-4257.

Shimada, Y., Fischman, D. A. and Moscona, A. A. 1967. The fine structure of embryonic chick skeletal muscle cells differentiated in vitro. J. C. B. 35:445-453.
Sterrenburg, E., Turk, R., 't Hoen, P. A. C., van Deutekom, J. C. T., Boer, J. M., van Ommen, G. J. and den Dunnen, J. T. 2004. Large-scale gene expression analysis of human skeletal myoblast differentiation. Neuromuscul. Disord. 14:507-518.

Strouken, P. M. H., Oberink, J. W. and Bantjes, A. 1994. Culturing of BHK-21 cells in a medium containing adult bovine serum and pituitary extract-Comparison with other sera and purified growth factors. Methods in Cell Science. 16: 17-27.

Sadkowski, T., Jank, M., Zwierzchowski, L., Oprzadek, J. and Motyl, T. 2009. Transcriptomic index of skeletal muscle of beef breeds bulls.Journal Of Physiology And Pharmacology. 60 $: 15-28$.

Vicente, A. and Kenneth, W. 1996. Myogenin expression, cell cycle withdrawal, and phenotypic differentiation are temporally separable events that precede cell fusion upon myogenesis. The Journal of Cell Biology. 132:657-66.

Wright, W. E., Sassoon, D. A. and Lin, V. K. 1989. Myogenin, a factor regulating myogenesis, has a domain homologous to MyoD. Cell. 56:607-17.

W"ust, R. C., Morse, C. I., Haan, A., Jones, D. A. and Degens, H. 2007. Sex differences in contractile properties and fatigue resistance of human skeletal muscle. Exp Physiol 93:843-850.

Yaffe, D. and Saxel, O. 1997. A Myogenic Cell Line with Altered Serum Requirements for Differentiation. Differentiation. 7: 159-166.

Yoshioka, M., Boivin, A., Bolduc,. C. and St-Amand, J. 2007. Gender difference of androgen actions on skeletal muscle transcriptome. J Mol Endocrinol. 39:119-133.

(Received Jun. 8, 2012; Revised Jun. 18, 2012; Accepted Jun. 19, 2012) 